\title{
Antifungal activity and detailed chemical characterization of Cistus ladanifer phenolic extracts
}

\author{
Lillian Barros a,b,1 , Montserrat Dueñas ${ }^{\mathrm{b}, 1}$, Carlos Tiago Alves $^{\mathrm{c}}$, Sónia Silva ${ }^{\mathrm{c}}$, Mariana Henriques $^{\mathrm{c}}$, \\ Celestino Santos-Buelga ${ }^{\mathrm{b}}$, Isabel C.F.R. Ferreira ${ }^{\mathrm{a}, *, 1}$ \\ a CIMO/Escola Superior Agrária, Instituto Politécnico de Bragança, Campus de Santa Apolónia, Apartado 1172, 5301-855 Bragança, Portugal \\ b Grupo de Investigación en Polifenoles (GIP-USAL), Facultad de Farmacia, Universidad de Salamanca, Campus Miguel de Unamuno, 37007 Salamanca, Spain \\ c IBB - Institute for Biotechnology and Bioengineering, Centre of Biological Engineering, University of Minho, 4710-057 Braga, Portugal
}

\section{A R T I C L E I N F O}

\section{Article history:}

Received 10 February 2012

Received in revised form 27 March 2012

Accepted 29 March 2012

\section{Keywords:}

Cistus ladanifer

Phenolic compounds

HPLC-DAD-ESI/MS

Candida species

Antifungal activity

\begin{abstract}
A B S T R A C T
The life-threatening mycoses caused by opportunistic fungal pathogens (mainly species from the genus Candida) associated with nosocomial infections, are one of the major health problems in our days. Therefore, it is crucial to identify new compounds, especially natural ones, that are active against the most broaden spectrum of Candida species. Herein, a screening of the antifungal potential of a phenolic extract of Cistus ladanifer from Northeastern Portugal, against Candida species was performed. Furthermore, the extract was characterized by HPLC-DAD-ESI/MS. Phenolic acids and derivatives $(3.96 \mathrm{mg} / \mathrm{g}$ extract), ellagic acid derivatives ( $30.34 \mathrm{mg} / \mathrm{g}$ extract), and flavonoids ( $4.15 \mathrm{mg} / \mathrm{g}$ extract), such as catechins, flavonols and flavones, were found in the sample. The most abundant group was ellagic acid derivatives in which punicalagin gallate, a derivative of punicalagin attached to gallic acid, was found in highest amount $(15.99 \pm 0.02 \mathrm{mg} / \mathrm{g}$ extract). These compounds (i.e., ellagitannins) could be related to the strong inhibition of Candida albicans, C. glabrata and C. parapsilosis growth (MIC $<0.05 \mathrm{mg} / \mathrm{mL}$ ). Moreover, the best antifungal activity was against $C$. glabrata, where the studied extract was able to cause at least $3 \log$ of reduction at concentrations below $0.05 \mathrm{mg} / \mathrm{mL}$ and a total growth inhibition at concentrations above $0.625 \mathrm{mg} / \mathrm{mL}$.
\end{abstract}

(c) 2012 Elsevier B.V. All rights reserved.

\section{Introduction}

Nosocomial infections are one of the major health problems in our days, being the life-threatening mycoses caused by opportunistic fungal pathogens associated with those infections, and the most prevalent species from the genus Candida (Calderone, 2002; Lass-Flör, 2009). In clinical practice, the most commonly encountered member of the genus is Candida albicans. However, several non-Candida albicans Candida (NCAC) spp., such as C. tropicalis, C. parapsilosis, and C. glabrata, have been increasingly implicated in human disease (Costa et al., 2010; Martins et al., 2010). This increased incidence can be attributed to improved identification methods but can also be a reflection of the high level of resistance often exhibited by NCAC species to antifungal agents (Gonzalez et al., 2008; Negri et al., 2009).

\footnotetext{
* Corresponding author. Tel.: +351 273303219, fax: +351273325405

E-mail address: iferreira@ipb.pt (I.C.F.R. Ferreira).

1 Both authors contributed equally to this work.
}

It has been reported the antimicrobial activity of several plants, related to their phenolic compounds (Rauha et al., 2000; Erasto et al., 2004; Tepe et al., 2004), including the antibacterial activity of Cistus ladanifer L. aqueous extracts containing ellagitannins (Barrajón-Catalán et al., 2010). This aromatic plant is a Mediterranean shrub from the Cistaceae family, having white flowers and viscid stems and leaves producing a fragrant oleoresin used in perfumes especially as a fixative. It is widely distributed in Portugal, being one of the most abundant species in the southern part of the country, occurring in large areas as pure dense stands (Teixeira et al., 2007). C. ladanifer and other species of Cistaceae are used as general remedies in folk medicine for treatment of various skin diseases, as antidiarrheics, and as anti-inflammatory agents (Attaguile et al., 2000).

As far as we know there are no reports on antifungal activity of the mentioned plant and the reports on phenolic composition refers to samples from Spain (Fernández-Arroyo et al., 2010; BarrajónCatalán et al., 2010, 2011). Herein, a screening of the antifungal potential of phenolic extracts of $C$. ladanifer against Candida species was performed, and the extracts were further characterized by HPLC-DAD-ESI/MS. 


\section{Materials and methods}

\subsection{Samples}

C. ladanifer fresh leaves from flowering steams were collected randomly, from wild plants growing in the Natural Park of Montesinho (Northeastern Portugal) in July 2008.

Morphological key characters from the Flora Iberica were used for plant identification: C. ladanifer (Castroviejo, 2005). Voucher specimens from each plant were numbered and deposited in the Herbarium of the ESA. The vegetal material was lyophilized (Ly-8FM-ULE, Snijders, Netherlands) and stored in the deep-freezer at $-20^{\circ} \mathrm{C}$ for subsequent analysis.

\subsection{Standards and reagents}

HPLC-grade acetonitrile was obtained from Merck KgaA (Darmstadt, Germany). Formic and acetic acids were purchased from Prolabo (VWR International, France). The phenolic compounds standards (apigenin-6-C-glucoside, catechin, ellagic acid, gallic acid, kaempferol-7-O-neohesperidoside, quercetin-3-O-glucoside, vanillic acid) were from Extrasynthese (Genay, France). RPMI 1640 medium was from Sigma (St. Louis, MO). Water was treated in a Milli-Q water purification system (TGI Pure Water Systems, USA).

\subsection{Preparation of the phenolic extracts}

The sample $(1 \mathrm{~g})$ was extracted with $30 \mathrm{~mL}$ of methanol:water $80: 20(\mathrm{v} / \mathrm{v})$ at room temperature, $150 \mathrm{rpm}$, for $1 \mathrm{~h}$. The extract was filtered through Whatman $\mathrm{n}^{\circ} 4$ paper, and the residue was reextracted twice. The combined extracts were evaporated at $35^{\circ} \mathrm{C}$ (rotary evaporator Büchi R-210) to remove methanol. The aqueous phase was lyophilized and re-dissolved in (a) $20 \%$ aqueous methanol at $5 \mathrm{mg} / \mathrm{mL}$ and filtered through a $0.22-\mu \mathrm{m}$ disposable LC filter disk for High Performance Liquid Chromatography (HPLC) analysis, or (b) distilled water at $200 \mathrm{mg} / \mathrm{mL}$ for antifungal assays.

\subsection{Phenolic compounds identification and quantification}

The extracts were analysed using a Hewlett-Packard 1100 chromatograph (Agilent Technologies) with a quaternary pump and a diode array detector (DAD) coupled to an HP Chem Station (rev. A.05.04) data-processing station. A Waters Spherisorb S3 ODS-2 $\mathrm{C} 18,3 \mu \mathrm{m}(4.6 \mathrm{~mm} \times 150 \mathrm{~mm})$ column thermostatted at $25^{\circ} \mathrm{C}$ was used. The solvents used were: (A) $2.5 \%$ acetic acid in water, (B) $2.5 \%$ acetic acid/acetonitrile (90:10, v/v) and (C) HPLC-grade acetonitrile. The elution gradient established was $0-100 \%$ B for $5 \mathrm{~min}$, from 0 to $5 \% \mathrm{C}$ for $35 \mathrm{~min}$, from 5 to $50 \% \mathrm{C}$ for $5 \mathrm{~min}$, isocratic $50 \% \mathrm{C}$ for $5 \mathrm{~min}$, and re-equilibration of the column, using a flow rate of $0.5 \mathrm{~mL} / \mathrm{min}$. Double online detection was carried out in the DAD using $280 \mathrm{~nm}$ and $370 \mathrm{~nm}$ as preferred wavelengths and in a mass spectrometer (MS) connected to HPLC system via the DAD cell outlet.

MS detection was performed in an API 3200 Qtrap (Applied Biosystems, Darmstadt, Germany) equipped with an ESI source and a triple quadrupole-ion trap mass analyzer that was controlled by the Analyst 5.1 software. Zero grade air served as the nebulizer gas (30 psi) and turbo gas for solvent drying $\left(400^{\circ} \mathrm{C}, 40 \mathrm{psi}\right)$. Nitrogen served as the curtain ( $10 \mathrm{psi}$ ) and collision gas (medium). The quadrupols were set at unit resolution. The ion spray voltage was set at $-4000 \mathrm{~V}$ in the negative mode. The MS detector was programmed for recording in two consecutive modes: Enhanced MS (EMS) and enhanced product ion (EPI) analysis. EMS was employed to achieve a full scan spectra, allowing an overview of all the ions present in sample. Settings used were: declustering potential (DP) $-40 \mathrm{~V}$, entrance potential (EP) $-7 \mathrm{~V}$, collision energy (CE) - 20 V. EPI mode was performed in order to obtain the fragmentation pattern of the parent ion(s) in the previous scan using the following parameters: DP $-40 \mathrm{~V}, \mathrm{EP}-10 \mathrm{~V}, \mathrm{CE}-25 \mathrm{~V}$, and collision energy spread (CES) $0 \mathrm{~V}$. Spectra were recorded in negative ion mode between $\mathrm{m} / z 100$ and 1400 .

The phenolic compounds present in the samples were characterised according to their UV and mass spectra and retention times compared with commercial standards when available. For the quantitative analysis of phenolic compounds, a calibration curve was obtained by injection of known concentrations $(1-100 \mu \mathrm{g} / \mathrm{mL})$ of different standards compounds: apigenin-6-C-glucoside $\left(y=517.4 x+268.26 ; R^{2}=0.9921\right) ;$ catechin $(y=161.23 x+177.26$; $\left.R^{2}=0.9992\right) ; \quad$ ellagic acid $\left(y=36.81 x+257.13 ; \quad R^{2}=0.9979\right)$; gallic acid $\left(y=298.26 x-634.14 ; \quad R^{2}=0.9949\right) ; \quad$ kaempferol7-O-neohesperidoside $\quad\left(y=279.99 x+404.53 ; \quad R^{2}=0.9902\right)$; quercetin-3-O-glucoside $\quad\left(y=363.45 x+117.86 ; \quad R^{2}=0.9994\right)$; vanillic acid $\left(y=364.98 x+603.85 ; R^{2}=0.9985\right)$. The results were expressed in $\mathrm{mg}$ per $\mathrm{g}$ of extract, as mean \pm standard deviation of three independent analyses.

\subsection{Antifungal activity}

Four reference strains from the American Type Culture Collection (ATCC), namely C. albicans (ATCC 90028), Candida tropicalis (ATCC 750), Candida glabrata (ATCC 2001) and Candida parapsilosis (ATCC 22019) were used. Before each experiment, all reference species were grown on Sabouraud Dextrose Agar (SDA; Merck, Germany) for $24 \mathrm{~h}$ at $37^{\circ} \mathrm{C}$. Yeast cells from at least five colonies ( $1 \mathrm{~mm}$ diameter) were suspended in $5 \mathrm{~mL}$ of sterile saline solution $(0.85 \%)$ and the resulting yeast suspension was mixed for $15 \mathrm{~s}$ in a vortex. Then, the suspensions were adjusted by spectrophotometric method, adding saline solution to reach the value of 0.5 in the McFarland scale corresponding to a final concentration of $3.0 \pm 2.0 \times 10^{6}$ cells $/ \mathrm{mL}$. The minimal inhibitory concentration (MIC) was determined according with the guidelines from the National Committee for Clinical Laboratory Standards (NCCLS), M27-A2 document (NCCLS, 2002) with some modifications. Briefly, serial dilutions of plant extract stock solutions were prepared in RPMI 1640 medium (Sigma, St Louis, MO), buffered to pH 7 and ranging from 0.05 to $5 \mathrm{mg} / \mathrm{mL}$. Aliquots of the extract $(100 \mu \mathrm{L})$, at a twofold final concentration, and Candida species suspensions $(100 \mu \mathrm{L})$ were mixed in the 96 -well plates (Orange Scientific, Braine-l' Alleud, Belgium). The MIC values and the colony forming units (CFUs) were determined after $48 \mathrm{~h}$ of incubation at $37^{\circ} \mathrm{C}$. Drug-free and yeast controls were also included.

\section{Results and discussion}

The difficulties associated with the management of Candida infections have been increasing during the last decades due to their low susceptibility to the available antifungal therapies (Ruhnke, 2006; Naeini et al., 2009). Thus, in order to overcome this problem it is of major importance to identify new compounds, especially natural ones, that are active against the most broaden spectrum of Candida species. Herein, phenolic extracts from $C$. ladanifer were explored as a source of antifungal agents. The phenolic composition of the sample was characterized as containing phenolic acids and derivatives, ellagic acid derivatives and flavonoids (Fig. 1 and Table 1).

Among phenolic acids and derivatives, peaks 1,2 and 6 were determined as galloyl glucose isomers, presenting a pseudomolecular ion $[\mathrm{M}-\mathrm{H}]^{-}$at $\mathrm{m} / \mathrm{z} 331$ that released an $\mathrm{MS}^{2}$ fragment at $\mathrm{m} / \mathrm{z}$ 169 ([M-162 $]^{-}$, loss of a hexose moiety) corresponding to gallic acid. Similarly, peak 7 was characterized as digalloyl-glucose. Peak 5 presented a pseudomolecular ion $[\mathrm{M}-\mathrm{H}]^{-}$at $\mathrm{m} / \mathrm{z} 315$ releasing a unique $\mathrm{MS}^{2}$ fragment at $\mathrm{m} / \mathrm{z} 153\left([\mathrm{M}-162]^{-}\right)$and was 


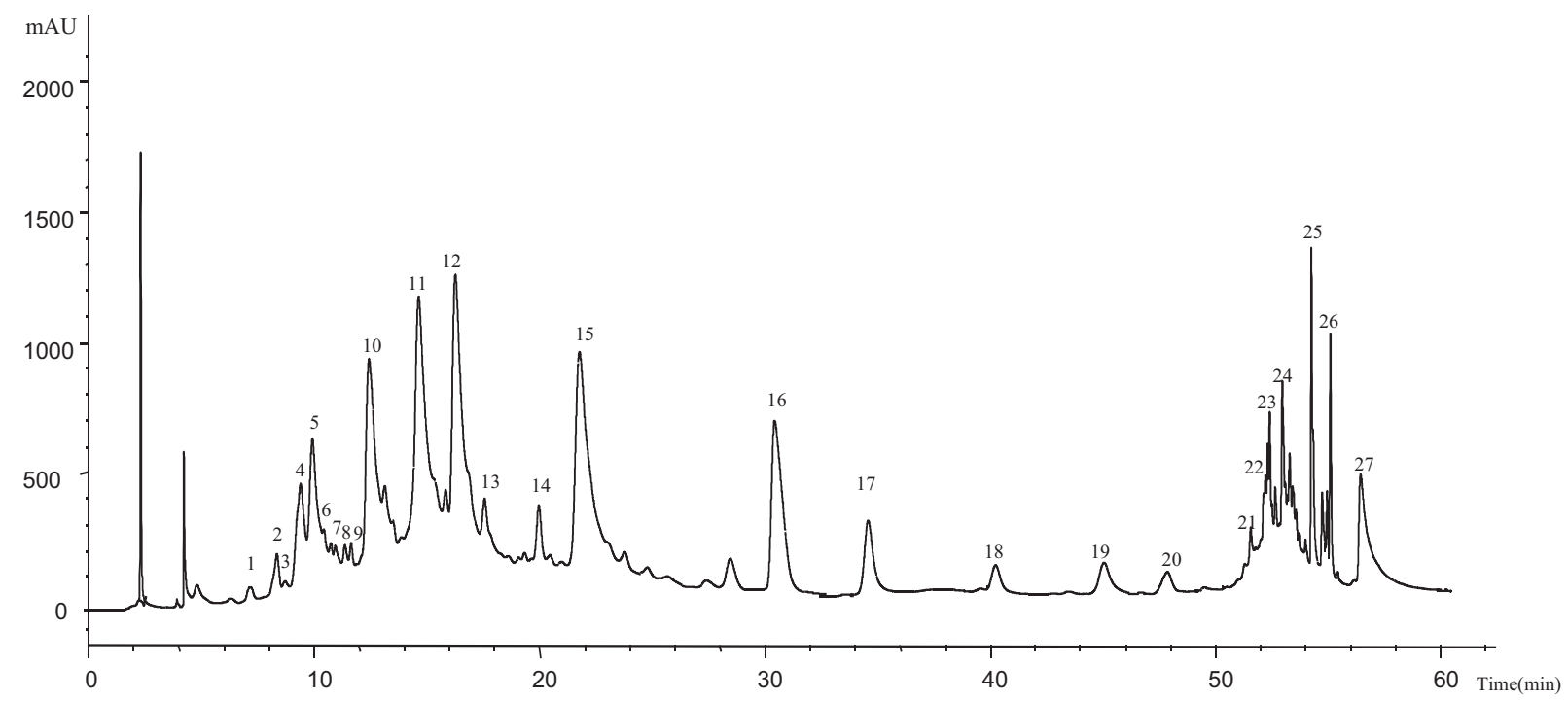

Fig. 1. HPLC chromatogram of the $C$. ladanifer extract, recorded at $280 \mathrm{~nm}$.

assigned to gentisoyl glucoside, based on a previous identification by Fernández-Arroyo et al. (2010). Peaks 9 and 24 corresponded to vanillic and ellagic acids, respectively, identified by comparison of their UV and mass spectra and retention time with commercial standards.

Various peaks were identified as ellagitannins. Peaks 10 and 12 were assigned to punicalagin isomers according to their pseudomolecular ion $\left([\mathrm{M}-\mathrm{H}]^{-}\right.$at $m / z$ 1083) and fragmentation pattern as described by Seeram et al. (2005) and Fernández-Arroyo et al. (2010). Similarly, peaks 3 and $4\left([\mathrm{M}-\mathrm{H}]^{-}\right.$at $\left.\mathrm{m} / \mathrm{z} 781\right)$ were identified as punicalin isomers (Seeram et al., 2005), and peak $14\left([\mathrm{M}-\mathrm{H}]^{-}\right.$at $\left.m / z 1085\right)$ as cornusiin $\mathrm{B}$, already described in C. ladanifer by Fernández-Arroyo et al. (2010). Peaks 11 and 15 $\left([\mathrm{M}-\mathrm{H}]^{-}\right.$at $m / z$ 1251) were tentatively identified as derivatives

\section{Table 1}

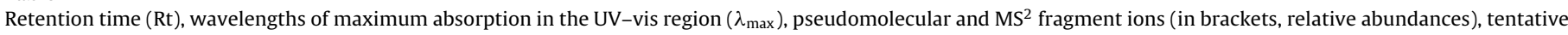
identification and quantification of the phenolic compounds in the studied $C$. ladanifer extract.

\begin{tabular}{|c|c|c|c|c|c|c|}
\hline Peak & $\operatorname{Rt}(\min )$ & $\lambda_{\max }(\mathrm{nm})$ & $\begin{array}{l}\text { Pseudomolecular } \\
\text { ion }[\mathrm{M}-\mathrm{H}]^{-}(\mathrm{m} / \mathrm{z})\end{array}$ & $\operatorname{MS}^{2}(m / z)$ & Tentative identification & $\begin{array}{l}\text { Quantification }^{\mathrm{a}} \\
\text { (mg/g, extract) }\end{array}$ \\
\hline 1 & 7.74 & 280 & 331 & $331(100), 169(14), 125(33)$ & Galloyl glucose & $0.76 \pm 0.02$ \\
\hline 2 & 8.80 & 270 & 331 & $331(33), 169(100), 125(37)$ & Galloyl glucose & $1.35 \pm 0.09$ \\
\hline 3 & 9.4 & 260,380 & 781 & 781(100), 721(7), 601(23), 299(10) & Punicalin isomer 1 & $0.07 \pm 0.01$ \\
\hline 4 & 9.78 & 260,381 & 781 & 781(100), 721(7), 601(35), 299(15) & Punicalin isomer 2 & $0.32 \pm 0.07$ \\
\hline 5 & 10.29 & 260,312 & 315 & $153(91), 109(27)$ & Gentisoyl hexoside & $\mathrm{nq}$ \\
\hline 6 & 10.75 & 278 & 331 & $169(100), 125(63)$ & Galloyl glucose & $0.87 \pm 0.05$ \\
\hline 7 & 11.21 & 243, sh297, 339 & 483 & $331(40), 169(100), 125(23)$ & Digalloyl glucose & $0.78 \pm 0.05$ \\
\hline 8 & 11.63 & 273 & 305 & $219(45), 179(41), 125(100)$ & Gallocatechin & $0.48 \pm 0.05$ \\
\hline 9 & 11.90 & 252,290 & 167 & $152(100), 123(15)$ & Vanillic acid & $0.05 \pm 0.01$ \\
\hline 10 & 12.61 & 258,380 & 1083 & $781(17), 601(16), 301(100)$ & Punicalagin isomer 1 & $5.90 \pm 0.15$ \\
\hline 11 & 14.65 & 259,378 & 1251 & 1083(4), 781(13), 601(4), 301(13) & Punicalagin gallate 1 & $7.89 \pm 0.29$ \\
\hline 12 & 16.17 & 260,379 & 1083 & $781(12), 601(25), 301(93)$ & Punicalagin isomer 2 & $7.90 \pm 0.19$ \\
\hline 13 & 17.42 & 274 & 305 & $219(33), 179(33), 125(100)$ & Epigallocatechin & $1.59 \pm 0.21$ \\
\hline 14 & 19.65 & 240,378 & 1085 & $783(10), 542(44), 451(46), 301(100)$ & Cornusiin B & $0.15 \pm 0.02$ \\
\hline 15 & 21.34 & 258,380 & 1251 & $1083(6), 781(4), 601(19), 301(33)$ & Punicalagin gallate 2 & $8.10 \pm 0.31$ \\
\hline 16 & 29.38 & 276 & 327 & $327(59), 165(100)$ & $\begin{array}{l}\text { 3,4'-Dihydroxypropiophenone- } \\
3-\beta \text {-D-glucoside }\end{array}$ & nq \\
\hline 17 & 34.53 & 338 & 593 & 473(30), 383(31), 353(66) & $\begin{array}{l}\text { Apigenin-6-C-glucose-8- } C \text { - } \\
\text { glucose }\end{array}$ & $0.53 \pm 0.01$ \\
\hline 18 & 40.24 & 348 & 595 & $301(100)$ & $\begin{array}{l}\text { Quercetin-O-hexoside-O- } \\
\text { pentoside }\end{array}$ & $0.26 \pm 0.00$ \\
\hline 19 & 45.01 & 348 & 625 & $463(84), 301(100)$ & $\begin{array}{l}\text { Quercetin-O-hexoside-O- } \\
\text { hexoside }\end{array}$ & $0.40 \pm 0.02$ \\
\hline 20 & 47.83 & 334 & 609 & 447(29), 285(58) & $\begin{array}{l}\text { Kaempferol-O-hexoside-O- } \\
\text { hexoside }\end{array}$ & $0.06 \pm 0.00$ \\
\hline 21 & 51.51 & 356 & 595 & $301(100)$ & $\begin{array}{l}\text { Quercetin-O-hexoside-O- } \\
\text { pentoside }\end{array}$ & $0.08 \pm 0.01$ \\
\hline 22 & 52.29 & 360 & 463 & $301(100)$ & Quercetin-3-O-glucoside & $0.14 \pm 0.00$ \\
\hline 23 & 52.38 & 354 & 433 & $301(100)$ & Quercetin- $O$-pentoside & $0.16 \pm 0.00$ \\
\hline 24 & 53.19 & 294,358 & 301 & $256(6), 185(15)$ & Ellagic acid & $0.15 \pm 0.02$ \\
\hline 25 & 53.28 & 334 & 475 & $313(100)$ & $\begin{array}{l}\text { Kaempferol dimethylether } \\
\text { hexoside }\end{array}$ & $0.06 \pm 0.00$ \\
\hline 26 & 54.24 & 334 & 593 & $447(8), 285(100)$ & Kaempferol-O-rutinoside & $0.06 \pm 0.00$ \\
\hline 27 & 56.45 & 350 & 299 & 285(100), 255(57), 227(29) & Kaempferol methylether & $0.32 \pm 0.02$ \\
\hline
\end{tabular}

nq - not quantified.

a The results were expressed in mg per $g$ of extract, as mean \pm standard deviation of three independent analyses. 
of punicalagin attached to gallic acid, previously reported in Cistus species by Saracini et al. (2005). In this case the gallic acid would not be bound to punicalagin by the carboxyl group, as denoted by the fragment at $m / z 1083$ corresponding to the loss of gallic acid itself. These compounds were not identified in the sample of $C$. ladanifer analyzed by Fernández-Arroyo et al. (2010).

Considering flavonoids, peaks 8 and 13 showed $\lambda_{\max }$ at $274 \mathrm{~nm}$ characteristic of prodelphinidins with a pseudomolecular ion $[\mathrm{M}-\mathrm{H}]^{-}$at $m / z 305$, were identified as gallocatechin and epigallocatechin (flavan-3-ols) by comparison with our data library. Peaks $18,19,21,22$ and 23 were identified as quercetin derivatives ( $\lambda$ max around $350-360 \mathrm{~nm}$, and $\mathrm{MS}^{2}$ fragment at $m / z$ 301). Peak $22\left([\mathrm{M}-\mathrm{H}]^{-}\right.$at $\left.m / z 463\right)$ was positively identified as quercetin-3$O$-glucoside by comparison with a commercial standard. Peak 23 $\left([\mathrm{M}-\mathrm{H}]^{-}\right.$at $\left.m / z 433\right)$ was associated to a quercetin- $O$-pentoside, and peaks 18 and $21\left([\mathrm{M}-\mathrm{H}]^{-}\right.$at $\left.m / z 595\right)$ to quercetin- $O$-hexosidepentosides, in which the sugar moieties constituted a disaccharide as deduced from the release of a unique MS $^{2}$ fragment. Peak 19 presented a pseudomolecular ion $[\mathrm{M}-\mathrm{H}]^{-}$at $m / z 625$, showing two fragments at $m / z 463$ and 301 corresponding to the losses of one and two a hexosyl residue, respectively, which allowed identifying it as a quercetin- $O$-hexoside- $O$-hexoside (sugars located at different positions on quercetin).

Peaks 20 and 26 corresponded to kaempferol derivatives $(\lambda \max$ around $334 \mathrm{~nm}$, and $\mathrm{MS}^{2}$ fragment at $\left.m / z 285\right)$. Peak $20\left([\mathrm{M}-\mathrm{H}]^{-}\right.$at $\mathrm{m} / z 609$ ) was characterised as kaempferol- $O$-hexoside- $O$-hexoside based on its fragmentation pattern similar to peak 19. Peak 26 presented a pseudomolecular ion $[\mathrm{M}-\mathrm{H}]^{-}$at $\mathrm{m} / \mathrm{z} 593$ that released fragments at $m / z 447\left([\mathrm{M}-\mathrm{H}-146]^{-}\right.$, loss of a rhamnosyl moiety) and 285 ([M-H-146-162 $]^{-}$, loss of a hexosyl moiety). The fact that no fragment resulting from the exclusive loss of hexosyl residue pointed to that the rhamnose was not directly to the aglycone but the two glycosyl moieties are constituting a disaccharide. Indeed, this fragmentation pattern is characteristic of flavonoid rutinosides, in which the 1-6 linkage between rhamnose and glucose allows for free rotation being more accessible to fragmentation than other disaccharides (Giusti et al., 1999). Therefore, the peak was tentatively identified as a kaempferol-O-rutinoside.

Peak 25 presented a pseudomolecular ion $[\mathrm{M}-\mathrm{H}]^{-}$at $\mathrm{m} / \mathrm{z} 475$ releasing a fragment at $m / z 313\left([\mathrm{M}-\mathrm{H}-162]^{-}\right.$coherent with a kaempferol dimethylether aglycone), which was identified by Fernández-Arroyo et al. (2010) in a sample of C. ladanifer. Thus, the compound was assigned to a kaempferol-dimethylether hexoside. A peak with a pseudomolecular ion $[\mathrm{M}-\mathrm{H}]^{-}$at $\mathrm{m} / \mathrm{z} 475$ was also detected by those authors in C. ladanifer although they did not offer any tentative identity. Peak $27\left([\mathrm{M}-\mathrm{H}]^{-}\right.$at $\left.m / z 299\right)$ was identified as a methylether of kaempferol based on the production of a major $\mathrm{MS}^{2}$ fragment at $m / z 285$ ([M-H-14 $]^{-}$, loss of a methyl residue).

Peak 17 showed a pseudomolecular ion $[\mathrm{M}-\mathrm{H}]^{-}$at $m / z 593$ that released three $\mathrm{MS}^{2}$ fragments ions at $m / z 473$ and 383, corresponding to loss of 120 and $90 \mathrm{amu}$, characteristic of $C$-hexosyl flavones, and at $m / z 353$ that might correspond to an apigenin aglycone bearing some sugar residues [apigenin $+83 \mathrm{mu}$ ] that remained linked to it (Ferreres et al., 2003). A compound with similar mass characteristics was found by Barrajón-Catalán et al. (2011) in C. ladanifer and associated to a diglycosylated apigenin. Since the two hexosyl residues are $C$-attached, it might be tentatively identified as apigenin-6-C-glucose-8-C-glucose.

Finally, peak $16\left([\mathrm{M}-\mathrm{H}]^{-}\right.$at $\left.m / z 327\right)$ was assigned to $3,4^{\prime}-$ dihydroxypropiophenone-3- $\beta$-D-glucoside as previously reported in C. ladanifer by Fernández-Arroyo et al. (2010).

Herein, it was found a similar profile to the ones reported by Fernández-Arroyo et al. (2010) and Barrajón-Catalán et al. $(2010,2011)$ in aqueous extracts of Spanish C. ladanifer samples. Nevertheless, some compounds reported by those authors (digalloyl- $\beta$-D-glucopiranose, pedunculagin, uralenneoside,

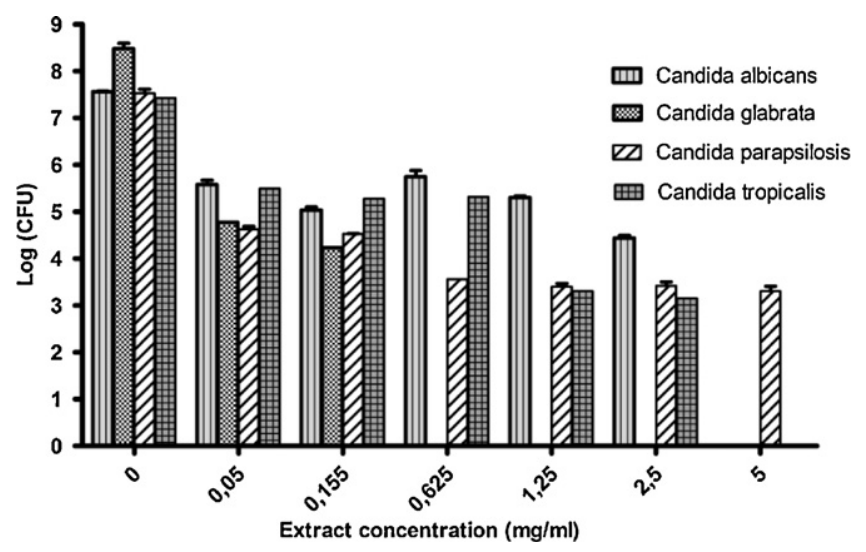

Fig. 2. Logarithm of number cells of C. albicans, C. glabrata, C. parapsilosis and C. tropicalis, grown in the presence of different concentrations of $C$. ladanifer phenolic extract, in SDB after $48 \mathrm{~h}$. Error bars represent standard deviation.

strictinin, mirciaphenone $B$, ellagic acid-7-xyloside, ducheside $\mathrm{A}$, apigenin and apigenin methylether) were not detected in our sample, which in turns contained others (punicalagin gallate, quercetin- $O$-hexoside- $O$-pentoside, quercetin- $O$-pentoside and kaempferol-O-rhamnoside-O-hexoside) that were not cited in the Spanish samples.

Fernández-Arroyo et al. (2010) and Barrajón-Catalán et al. (2011) did not perform the quantification of individual compounds, so it is not possible to compare quantities found in both samples. Barrajón-Catalán et al. (2011) performed only the quantification of four compounds and expressed the results as percentages $(0.242 \% \pm 0.004(\mathrm{w} / \mathrm{w})$ of gallic acid, and $3.50 \% \pm 0.02$ for the sum of three ellagitannins including punicalin and punicalagin), being also difficult the comparison of the results. The sample studied herein presented a total amount of phenolic compounds of $38.44 \mathrm{mg} / \mathrm{g}$ extract, distributed in phenolic acids and derivatives (3.96 mg/g), ellagic acid derivatives $(30.34 \mathrm{mg} / \mathrm{g}$ ) and flavonoids ( $4.15 \mathrm{mg} / \mathrm{g}$ ). The most abundant group was ellagic acid derivatives in which punicalagin gallates (peaks 11 and $15,7.89 \pm 0.29$ and $8.10 \pm 0.31 \mathrm{mg} / \mathrm{g}$ extract, respectively) were the compounds found in highest amount.

The in vitro activity of the studied C. ladanifer extract against four Candida species was evaluated. Aligiannis et al. (2001) proposed a classification for plant extracts effect against Candida species based on MIC values obtained in: strong inhibitors (MIC up to $0.5 \mathrm{mg} / \mathrm{mL}$ ), moderate inhibitors (MIC between 0.6 and $1.5 \mathrm{mg} / \mathrm{mL}$ ), and weak inhibitors (MIC above $1.6 \mathrm{mg} / \mathrm{mL}$ ). According to that distribution, the phenolic extract of $C$. ladanifer would act as a strong inhibitor of $C$. albicans, $C$. glabrata and $C$. parapsilosis growth (MIC $<0.05 \mathrm{mg} / \mathrm{mL})$, and as a moderate inhibitor of $C$. tropicalis growth (MIC $=0.625 \mathrm{mg} / \mathrm{mL}$ ). Bruni et al. (2003) also demonstrated that C. albicans ATCC 48274 was markedly inhibited by oils rich in phenolics, aldehydes and alcohols. The results of chemical characterization (Table 1) shows that the studied $C$. ladanifer extract was mostly constituted by phenolic compounds, which would thus explain its antifungal activity caused by $C$. ladanifer extract against the Candida species under study.The number of viable Candida, determined by CFU enumeration, was determined using different concentration of $C$. ladanifer extract (Fig. 2), showing that the activity of this latter varied with the species. Specifically, the highest antifungal activity was against $C$. glabrata, where this extract was able to cause at least $3 \log$ of reduction at concentrations below $0.05 \mathrm{mg} / \mathrm{mL}$, and a total growth inhibition at concentrations above $0.625 \mathrm{mg} / \mathrm{mL}$. In the case of $C$. albicans and C. tropicalis, complete growth inhibition was only observed for the highest assayed concentration $(5 \mathrm{mg} / \mathrm{mL})$, indicating less susceptible of these species 
to C. ladanifer extract than C. glabrata. Nonetheless, the extract was able to cause a reduction of approximately $3 \log$ in $C$. albicans and $C$. tropicalis at concentrations above $0.155 \mathrm{mg} / \mathrm{mL}$. None of the extract concentrations tested was able to reduce completely the C. parapsilosis growth. This was very interesting considering the low MIC value $(0.05 \mathrm{mg} / \mathrm{mL})$ obtained for this species, indicating that even though its growth was impaired at $0.05 \mathrm{mg} / \mathrm{mL}$, in fact, cells were still viable.

No results concerning antifungal activity have been found in the literature for phenolic extracts of $C$. ladanifer. Barrajón-Catalán et al. (2010) reported antimicrobial activity against Gram-positive (Staphylococcus aureus) and Gram-negative (Escherichia coli) bacteria of $C$. ladanifer aqueous extract that was more active against Gram-positive bacteria.

Overall, the phenolic extract of $C$. ladanifer affected the growth of different Candida sp., suggesting that the compounds present in the extract could play an active role in the protection against fungi related to several diseases. Future work will include the evaluation of antifungal activity of those compounds (isolated from the plant or commercial compounds when available).

\section{Acknowledgements}

The authors are grateful to strategic project PEstOE/AGR/UI0690/2011 for financial support to CIMO. L. Barros thanks to FCT, POPH-QREN and FSE for her grant (SFRH/BPD/4609/2008). M. Dueñas thanks to the Programa Ramón y Cajal for a contract. The GIP-USAL is financially supported by the Spanish Ministerio de Ciencia e Innovación through the Consolider-Ingenio 2010 Programme (FUN-C-FOOD, CSD200700063), and Junta de Castilla y León (Grupo de Investigación de Excelencia, GR133).

\section{References}

Aligiannis, N., Kalpotzakis, E., Mitaku, S., Chinou, I.B., 2001. Composition and antimicrobial activity of the essential oils of two Origanum species. Journal of Agricultural and Food Chemistry 40, 4168-4170.

Attaguile, L.G., Russo, A., Campisi, A., Savoca, F., Acquaviva, R., Ragusa, N., Vanella, A., 2000. Antioxidant activity and protective effect on DNA cleavage of extracts from Cistus incanus L. and Cistus monspeliensis L. Cell Biology and Toxicology 16, 83-90.

Barrajón-Catalán, E., Fernández-Arroyo, S., Roldán, C., Guillén, E., Saura, D., SeguraCarretero, A., Micol, V., 2011. A systematic study of the polyphenolic composition of aqueous extracts deriving from several Cistus genus species: evolutionary relationship. Phytochemical Analysis 22, 303-312.

Barrajón-Catalán, E., Fernández-Arroyo, S., Saura, D., Guillén, E., FernándezGutiérrez, A., Segura-Carretero, A., Micol, V., 2010. Cistaceae aquous extracts containing ellagitannins show antioxidant and antimicrobial capacity, and cytotoxic activity against human cancer cells. Food and Chemical Toxicology 48, 2273-2282.

Bruni, R., Medici, A., Andreotti, E., Fantin, C., Muzzoli, M., Dehesa, M., Romagnolie, C., Sacchetti, G., 2003. Chemical composition and biological activities of Ishpingo essential oil, a traditional Ecuadorian spice from Ocotea quixos (Lam.) Kosterm. (Lauraceae) flower calices. Food Chemistry 85, 415-421.

Calderone, R., 2002. Introduction and historical perspectives. In: Calderone, R. (Ed.), Candida and Candidiasis. ASM Press, Washington, DC, pp. 15-25.

Castroviejo, S. (coord.), 2005. Flora Iberica, vol. III, 2a editión. Real Jardín Botánico, CSIC, Madrid.

Costa, A.R., Silva, F., Henriques, M., Azeredo, J., Oliveira, R., Faustino, A., 2010. Candida clinical species identification: molecular and biochemical methods. Annals of Microbiology 60, 105-112.

Erasto, P., Bojase-Moleta, G., Majinda, R.R., 2004. Antimicrobial and antioxidant flavonoids from the root wood of Bolusanthus speciosus. Phytochemistry 65, $875-880$.

Fernández-Arroyo, S., Micol, V., Segura-Carretero, A., Fernández-Gutiérrez, A., Barrajón-Catalán, E., 2010. High-performance liquid chromatography with diode array detection coupled to electrospray time-of-light and ion-trap tandem mass spectrometry to identify phenolic compounds from a Cistus ladanifer aqueous extract. Phytochemical Analysis 21, 307-313.

Ferreres, F., Silva, B.M., Andrade, P.B., Seabra, R.M., Ferreira, M.A., 2003. Approach to the study of C-glycosyl flavones by ion trapHPLC-PAD-ESI/MS/MS: application to seeds of quince (Cydonia oblonga). PhytochemicalAnalysis 14, 352-359.

Gonzalez, G.M., Eliondo, M., Ayala, J., 2008. Trends in species distribution and susceptibility of bloodstream isolates of Candida collected in Monterrey, Mexico, to seven antifungal agents: results of a 3-years (2004 to 2007) surveillance study. Journal of Clinical Microbiology 46, 2902-2905.

Giusti, M., Rodríguez-Saona, L., Griffin, D., Wrolstad, R., 1999. Electrospray and tandem mass spectroscopy as tools for anthocyanin characterization. Journal of Agricultural and Food Chemistry 47, 4657-4664.

Lass-Flör, L., 2009. The changing face of epidemiology of invasive fungal disease in Europe. Mycoses 52, 197-205.

Martins, M., Henriques, M., Ribeiro, A.P., Fernandes, R., Gonçalves, V., Seabra, A., Azeredo, J., Oliveira, R., 2010. Oral carriage of patients attending a dental clinic in Braga, Portugal. Revista Iberoamericana de Micología 27, 119-124.

Naeini, A., Khosravi, A.R., Chitsaz, M., Shkri, H., Kamlnejad, M., 2009. Anti-Candida albicans activity of some Iranian plants used in traditional medicine. Journal de Mycologie Médicale 19, 168-172.

NCCLS (National Committee for Clinical Laboratory Standards), 2002. Reference Method for Broth Dilution Antifungal Susceptibility Testing of Yeast. Approved Standard. NCCLS Document M27-A2. National Committee for Clinical Laboratory Standards, Wayne, PA.

Negri, M., Henriques, M., Svidzinski, T.I., Paula, C.R., Oliveira, R., 2009. Correlation between Etest ${ }^{\circledR}$, disk diffusion, and microdilution methods for antifungal susceptibility testing of Candida species from infection and colonization. Journal of Clinical Laboratory Analysis 23, 324-330.

Rauha, J.-P., Remes, S., Heinonen, M., Hopia, A., Kahkonen, M., Kujalac, Y., Pihlajac, K., Vuorela, H., Vuorela, P., 2000. Antimicrobial effects of Finnish plant extracts containing flavonoids and other phenolic compounds. International Journal of Food Microbiology 56, 3-12.

Ruhnke, M., 2006. Epidemiology of Candida albicans infections and role of nonCandida albicans yeasts. Current Drug Targets 7, 495-504.

Saracini, E., Tattini, M., Traversi, M.L., Vincieri, F.F., Pinelli, P., 2005. Simultaneous LC-DAD and LC-MS determination of ellagitannins, flavonoid glycosides, and acyl-glycosyl flavonoids in Cistus salvifolius L. leaves. Chromatographia 62, 245-249.

Seeram, N., Lee, R., Hardy, M., Heber, D., 2005. Rapid large scale purification of ellagitannins from pomegranate husk, a by-product of the commercial juice industry. Separation and Purification Technology 41, 49-55.

Teixeira, S., Mendes, A., Alves, A., Santos, L., 2007. Simultaneous distillationextraction of high volatile compounds from Cistus ladanifer L. Analytica Chimica Acta 584, 439-446.

Tepe, B., Daferera, D., Sokmen, M., Polissiou, M., Sokmen, A., 2004. In vitro antimicrobial and antioxidant activities of the essential oils and various extracts of Thymus eigii. Journal of Agricultural and Food Chemistry 52, 1132-1137. 